\title{
The Black Aspergillus Species of Maize and Peanuts and Their Potential for Mycotoxin Production
}

\author{
Edwin R. Palencia ${ }^{1}$, Dorothy M. Hinton ${ }^{2}$ and Charles W. Bacon ${ }^{2, *}$ \\ Department of Plant Pathology, University of Georgia, Athens, GA, USA \\ 2 Toxicology \& Mycotoxin Research Unit, USDA, ARS, Russell Research Center, P.O. Box 5677, \\ Athens, GA, USA
}

* Author to whom correspondence should be addressed; E-Mail: charles.bacon@ars.usda.gov; Tel.: +1-706-546-3142; Fax: +1-706-546-3116.

Received: 27 January 2010; in revised form: 15 March 2010 / Accepted: 19 March 2010 /

Published: 24 March 2010

\begin{abstract}
The black spored fungi of the subgenera Circumdata, the section Nigri (=Aspergillus niger group) is reviewed relative to their production of mycotoxins and their effects on plants as pathogens. Molecular methods have revealed more than 18 cryptic species, of which several have been characterized as potential mycotoxin producers. Others are defined as benign relative to their ability to produce mycotoxins. However, these characterizations are based on in vitro culture and toxins production. Several can produce the ochratoxins that are toxic to livestock, poultry, and humans. The black aspergilli produce rots of grapes, maize, and numerous other fruits and grain and they are generally viewed as post-harvest pathogens. Data are review to suggest that black aspergilli, as so many others, are symptomless endophytes. These fungi and their mycotoxins contaminate several major grains, foodstuffs, and products made from them such as wine, and coffee. Evidence is presented that the black aspergilli are producers of other classes of mycotoxins such as the fumonisins, which are known carcinogenic and known prior investigations as being produced by the Fusarium species. Three species are identified in U.S. maize and peanuts as symptomless endophytes, which suggests the potential for concern as pathogens and as food safety hazards.
\end{abstract}


Keywords: Aspergillus niger; Aspergillus section Nigri; black aspergilli; fumonisins; ochratoxins; mycotoxins

\section{Introduction}

Fungi of the genus Aspergillus have a long history of associations with humankind. The genus was first described by Micheli in 1729 [1] to include those fungi with long stalks and spore heads that radiated in long chains from a central structure resembling an aspergillum, the brush-like structure used in religious ceremonies for sprinkling holy water. Species of this genus are common, originally applied to the first species of this genus, A. glaucus by Link [2]. They are extremely diverse in their habitats, and extraordinarily versatile in terms of their ability to produce secondary metabolites. Several are important human and plant pathogens, while others are useful in the production of several fermented food products highly regarded by humankind. Due to their metabolic versatility, species of this genus have great biotechnological potential and several are used for the production of numerous food and nonfood by-products. The plant pathogens are of concern not only for their ability to destroy several agronomically important food crops, but also due to their ability to produce several mycotoxins. These mycotoxins are associated with specific species or subgenera of the Aspergillus and are in general toxic to livestock, poultry, fish, and humans.

Early attention was devoted to species of Aspergillus as causes of animal toxicities, mainly poultry [3]. Immediately after this report, it was established that this toxicity, described as the Turkey-X disease of peanuts, was caused by A. flavus and A. parasiticus [4]. Subsequent studies resulted in identifying the aflatoxins as the toxicological agent [5], which initiated mycotoxicology as a serious and complex problem of food safety. Continued studies resulted in distinguishing another class of mycotoxins produced by species of aspergilli, the ochratoxins, which along with the aflatoxins, were established as important carcinogenic mycotoxins. Ochratoxin A was discovered in maize by Van der Merwe et al. [6] as the mycotoxin produced by strains of Aspergillus ochraceus Whilh, and Penicillium verrucosum. One of the first reports for the natural occurrences of ochratoxicosis was in poultry, which consisted of five independent episodes including about 970,000 turkeys, two episodes of about 70,000 laying hens, and two episodes in about $12,000,000$ broilers [7]. These observations served to establish ochratoxins as important toxins in agriculture, and in food safety. Recently the ochratoxins have been reported from several other species of Aspergillus sections Circumdati (A. ochraceus group), and by Eurotium herbariorum, a member of the Aspergillus section (A. glaucus group). Recently, the black species of Aspergillus have been shown able to produce the ochratoxins [8], which extends the geographic area of concern from the temperate zone to the tropical and sub-temperate zone due to the distribution of these black species.

The black aspergilli are commonly found as soil organisms decomposing dead plant residues [9] and they are pathogenic on several crops. As discussed below, the majority of the black Aspergillus species are associated with grapes, onions, maize, and peanuts, where they are cited as pathogens causing such diseases as peanut and maize seedling blight, and maize kernel rot. However, there are numerous 
examples of fungi associated with plants as symptomless endophytes, and there is evidence that this life habit may be practiced by the Aspergillus species as well. In association with several hosts, these symptomless endophytes have the capacity to either develop as pathogens or as saprophytes, and in either state become producers of mycotoxins. Symptomless expressions of several black aspergilli are indicated in the literature but nothing is indicated about their ability to produce mycotoxins and any associated pathology. Further, the black species of Aspergillus associated with any plant pathological problem was indicated in early publications as A. niger, the black species. In this review, we refer to A. niger sensu strictu, i.e., A. niger var. niger, to designate or distinguish the present day discription from the older published accounts, which in most instances were applied sensu lato and will be referred to here as simply A. niger. While several cryptic species within this subgenus have been delineated, this recent taxonomic revision creates a large gap of knowledge of black Aspergillus species that are presently defined, and which is important to food safety and plant pathology. This review focuses on identifying the species of the subgenera Circumdati, the section Nigri (=A. niger group) (Table 1) encountered on cereals and other plants, with an emphasis on maize and peanuts in particular. The nature of the association with their hosts and their potential to produce the ochratoxins and other toxins relative to specific species are also reviewed.

\section{The Black Aspergillus Species}

There are well over 190 number of Aspergillus species, and these can be conveniently separated into several distinct morphospecies, and several of these are based on colors according to the earlier classification of Raper and Fennell [10]. However, phylogenetic analyses of sequence data resulted in separating the Aspergillus genus into eight subgenera [11]. Following these analyses, the economically important species that produce the ochratoxins were divided to include those species of the subgenera Circumdati, the sections Circumdati (=Aspergillus ochraceus group) and Nigri (A. niger group). There are no known teleomorphic species of group Nigri. In recent years, members of the Aspergillus section Nigri have undergone an extensive taxonomic revision resulting in several new taxa, such as A. niger var. niger, A. melleus, A. sulphureus, A. brasilensis, A. ostianus, A. petrakii, A. scletotium, A. carbonarius, A. aculeatus, A. japonicus, A. tubingensis, A. ibericus and Eurotium herbariorum [12-14] (Table 1).

However, these new taxa have not been identified as to the responsible species in diseases of food crops, such as maize seedling blight, maize ear rot and seedling blight of peanuts. Further, any role they may play in the pathogenic expression of maize kernels and plants prior infected with Fusarium verticillioides, a common maize pathogen usually co-associated with black aspergilli as a symptomless infection, is unknown.

Klich [9] classic paper on the biography of the Aspergillus genus indicated that most of the species occurred in the tropical latitudes below 25 degree north and south, with greater than expected frequencies in the subtropical to warm temperate zones at latitudes between 26 and 35 degrees. This study suggested that species abundance peaked in the subtropics. This distribution is attributed to several biotic and abiotic interacting factors with the major factor temperature [9]. In general, the black species of aspergilli were found to occur more frequently in forest and cultivated soils and less frequency in desert soils. However, A. niger var. niger was uniformly distributed throughout the entire samples areas including forest, 
grassland, wetlands, deserts, and cultivated soils [9]. Thus, this documents this species as the most common species in both subgenera of Circumdati.

Table 1. Selected toxins isolated from black Aspergillus species, modified from Nielsen et al. [36].

\begin{tabular}{|c|c|c|c|}
\hline Species $^{\mathrm{a}}$ & Host $^{b}$ & Ochratoxin & $\begin{array}{l}\text { Biologically active } \\
\text { metabolites }\end{array}$ \\
\hline A. niger var. niger $^{c}$ & $\begin{array}{l}\text { Maize, peanuts, } \\
\text { grapes, and grape } \\
\text { products, coffee, tea, } \\
\text { beans, spices }{ }^{\mathrm{d}}\end{array}$ & $++^{\mathrm{i}}$ & $\begin{array}{l}\text { Fumonisin B2 } \\
\text { Fumonisin B4 } \\
\text { Nigragillin }^{\mathrm{e}} \\
\text { Malformin }^{\mathrm{f}}\end{array}$ \\
\hline A. carbonarius & $\begin{array}{l}\text { Grapes, java coffee } \\
\text { bean }\end{array}$ & + & Carbonarones $^{\mathrm{g}}$ \\
\hline A. tubingensis & Arabica coffee beans & + & Malformin, nigranillin \\
\hline A. brasiliensis & Grapes & - & Malformin \\
\hline A. acidus & Raisins & - & $\mathrm{Uk}$ \\
\hline A. ibericus & Grapes & - & Uk \\
\hline A homomorphus: & Soil, nh & - & Secalonic acid ${ }^{\mathrm{h}}$ \\
\hline A. ellipticus & Soil, nh & - & Terphenyllin $^{\mathrm{f}}$ \\
\hline A. aculeatinus & Arabica coffee bean & - & $\mathrm{Uk}$ \\
\hline A. aculeatus & Green Coffee bean & - & $\begin{array}{l}\text { Secalonic acid, } \\
\text { Aspergillusol } \mathrm{A}^{\mathrm{g}}\end{array}$ \\
\hline A. japonicus & Grapes, maize, peanut & + & Cycloclavin \\
\hline A. uvarum & Healthy grapes & - & Secalonic acid \\
\hline A. piperis & Black pepper & - & Aflavinines $^{\mathrm{e}}$ \\
\hline A. sclerotiicarbonarius & Robusta coffee bean & - & Uk \\
\hline A. sclerotioniger & Coffe bean & & Aflavinines \\
\hline A. heteromorphus & Soil, nh & - & Uk \\
\hline
\end{tabular}

${ }^{a}$ A. niger var. niger consists of several synonym including A. awamori, A. phoenicis, A. kawachii, A. saitoi, A. usamii, A. foetidus, A. citricus, and A. ficuum, and oftentimes these synonyms are listed by several authors as varieties of $A$. niger, i.e., A. niger var. awamori, and as such they are ochratoxin $A$ producer [36]. ${ }^{\mathrm{b}}$ Indicates the principle plant host associated with the species as a parasite if known, but does not preclude nor exclude soil and other saprophytic habitats, which is indicated as nh, no host known. ${ }^{c}$ Data indicated for this species may or may not reflect information on A. niger sensu stricto, rather the generalized descriptive placement of black aspergilli in this species complex. ${ }^{\mathrm{d}}$ The spices include isolations from various plant parts of black cumin, fennel, lime tree, absinthium, ginger, cinnamon, peppermint, carob tree, chamomile, saffron, curcuma, wormwood, rose, and lesser galangel [72]. ${ }^{\mathrm{e}}$ Insectidal. ${ }^{\mathrm{f}}$ Phytotoxic. ${ }^{\mathrm{g}}$ Antibiotic. ${ }^{\mathrm{h}} \mathrm{Weak}$ mycotoxic activity. ${ }^{\mathrm{i}}$ Symbols, +, -, present or absent; uk, unknown.

In a recent survey of maize and peanut using rep-PCR to distinguish morphotypic and molecularly derived species (Figure 1), several basic black Aspergilli were distinguished in peanuts and maize [15]. The survey was designed to analyze for endophytic species of these two plants using surface disinfection 
of kernels and plant parts. This survey indicated that several species were present in these two plants as seedborne systemic and endophytic infections (Table 2). This survey indicates that the A. niger var. niger was the major species isolated from these two plants, with A. foetidus and A. japonicus occurring as minor species. Peanuts accounted for three species, while only two were isolated from maize. The work is similar to that of Magnoli et al. [16] who found that of the black aspergilli, A. niger var. niger along with A. japonicus var. japonicus was isolated from surface disinfected maize kernels from Argentina.

\section{Mycotoxins Produced by Black Aspergillus sp.}

The earliest report of toxicity from the black Aspergillus species was by Frischbier and Richtesteiger [17] who reported on the experimental poisoning of pigs fed bread that was inoculated with $A$. niger and that the toxic component was oxalic acid. Later, Wilson and Wilson [18] indirectly indicated A. niger as the toxic organisms since oxalic acid was isolated from moldy feedstuffs that was toxic to livestock. Presently, the type of the section, A. niger, has important industrial application and most strains of this specific species hold the Generally Recognized as Safe status issued by FDA. What is not clear, however, what species is intended when the term "A. niger" is used for all black spored aspergilli. Thus, correct taxonomic descriptions of species within this group are extremely important as this can serve to distinguish those that are phytopathogens and mycotoxic from those that have technological applications.

\subsection{Ochratoxins}

Ochratoxin $\mathrm{A}$ is the more toxic of two dihydroisocoumarins initially isolated from broth cultures of A. ochraceus. The other is ochratoxin B, which is the dechlorinated analog of ochratoxin A. Both A and B occur in smaller amounts as the methyl and ethyl esters. Ochratoxin A is one of the world's most important mycotoxin, rated third of the top six, primarily due to the documented deaths of humans, primarily in Europe. The International Agency for Research on Cancer classifies this mycotoxin in the 2B group, possible carcinogen to humans [19], but it is not regulated in the United States, although it is in Europe (FAO Food and Nutrition Paper No. 81, 2004). Ochratoxin A is nephrotoxic, teratogenic, carcinogenic, and immunosuppressive in animals, and it is cytotoxic in hepatic cell lines. In humans, ochratoxin A has been associated with the Balkan Endemic Nephropathy, a tubule- interstitial nephropathy leading to a chronic renal failure that is characterized by high concentration of ochratoxin A in blood serum and urine of patients suffering from this disease [20].

In addition to the above in vivo description of toxicity from ochratoxin A, there is a recent finding of its mode of action at the cellular level. This toxin is reported to interact with tight junction pores, which regulate paracellular transport across cell and tissue membranes, by altering the four isoforms of cell-tocell specific cell membrane adhesion proteins called claudins [21]. Thus, this toxin affects cell membrane integrity, producing non-regulated transports in and out of cells. This can have a high economic impact at the agricultural level effecting food products ranging from eggshell damage to increase bacterial infections. 
Figure 1. Dendrogram and gel-like images illustrating rep-PCR barcodes of 54 Aspergillus section Nigri isolates, designated RRC from corn and peanuts samples, analyzed along with reference species of black aspergilli by a rep-PCR barcoding procedure [15]. Queried sample numbers are indicated by circles under the key column of this figure and the identifications of each sample ID number is indicated in Table 2 [15].

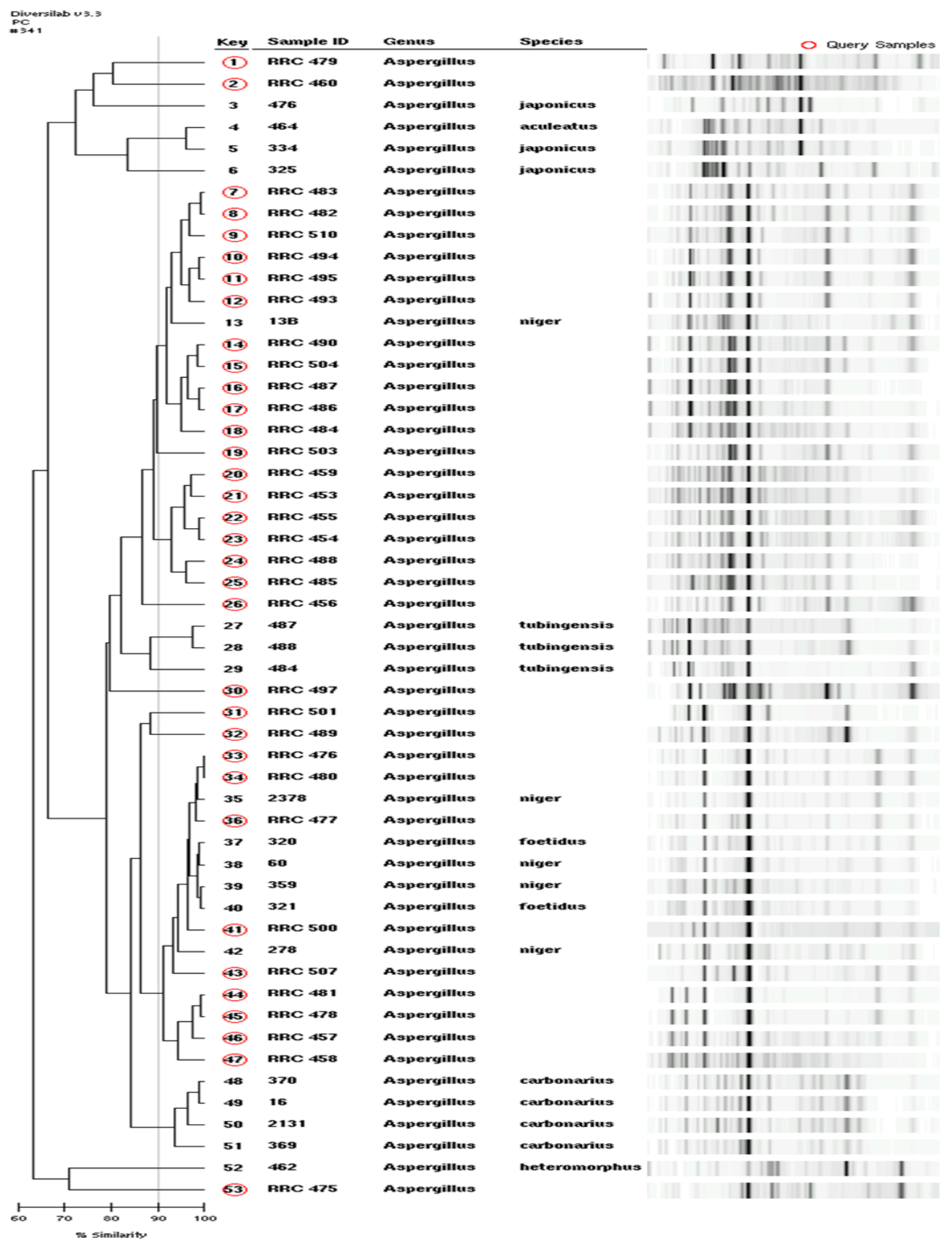


Table 2. Field collection of isolates with predicted species results depicted in Figure 1 [15].

\begin{tabular}{|c|c|c|}
\hline $\begin{array}{c}\text { Strain } \\
\text { Number }^{\mathrm{a}}\end{array}$ & Location & Species \\
\hline RRC 453 & Peanut, South Georgia & A. niger \\
\hline $\mathrm{RRC} 454$ & Peanut, South Georgia & A. foetidus \\
\hline $\mathrm{RRC} 455$ & Peanut, South Georgia & A. niger \\
\hline RRC 456 & Peanut, South Georgia & A. niger \\
\hline RRC 457 & Peanut, South Georgia & A. niger \\
\hline RRC 458 & Peanut, South Georgia & A. foetidus \\
\hline RRC 459 & Peanut, South Georgia & A. niger \\
\hline RRC 460 & Peanut, South Georgia & A. japonicus \\
\hline RRC 475 & Peanut slurries, Dawson, Georgia & A. niger \\
\hline RRC 476 & Peanut slurries, Dawson, Georgia & A. niger \\
\hline RRC 477 & Peanut slurries, Dawson, Georgia & A. foetidus \\
\hline RRC 478 & Peanut slurries, Dawson, Georgia & A. niger \\
\hline RRC 479 & Peanut slurries, Dawson, Georgia & A. japonicus \\
\hline RRC 480 & Peanut slurries, Dawson, Georgia & A. niger \\
\hline RRC 481 & Peanut slurries, Dawson, Georgia & A. niger \\
\hline RRC 482 & Maize kernels, Midwestern, USA & A. niger \\
\hline RRC 483 & Maize kernels, Midwestern, USA & A. niger \\
\hline RRC 484 & Maize kernels, Midwestern, USA & A. niger \\
\hline RRC 485 & Maize kernels, Midwestern, USA & A. niger \\
\hline RRC 486 & Maize, kernels, Midwestern, USA & A. niger \\
\hline RRC 487 & Maize kernels, Midwestern, USA & A. niger \\
\hline RRC 488 & Maize kernels, Midwestern, USA & A. niger \\
\hline RRC 489 & Maize kernels, Midwestern, USA & A. niger \\
\hline RRC 490 & Maize kernels, Midwestern, USA & A. niger \\
\hline RRC 493 & Maize kernels, Midwestern, USA & A. niger \\
\hline RRC 494 & Maize kernels, Midwestern, USA & A. niger \\
\hline RRC 495 & Maize kernels, Midwestern, USA & A. niger \\
\hline RRC 497 & Maize kernels, Midwestern, USA & A. niger \\
\hline RRC 500 & Maize kernels, Midwestern, USA & A. niger \\
\hline RRC 501 & Maize kernels, Midwestern, USA & A. niger \\
\hline RRC 503 & Maize kernels, Midwestern, USA & A. niger \\
\hline RRC 504 & Maize kernels, Midwestern, USA & A. niger \\
\hline RRC 507 & Maize kernels, Midwestern, USA & A. foetidus \\
\hline RRC 510 & Maize kernels, Midwestern, USA & A. niger \\
\hline
\end{tabular}

${ }^{\mathrm{a}} \mathrm{RRC}$, Russell Research Center culture collection, Athen, Ga.

\subsection{Ochratoxin contaminated products and producing species}

Ochratoxin A was isolated as a natural contaminant from maize [22], and since this report it has been isolated from many agronomically important crops, and processed food and feed. Commodities 
contaminated with this toxin predominantly include cereal and derived products including maize, wheat, rice, sorghum, mixed livestock, and poultry feed. Ochratoxin has also been found in green coffee beans, peanuts, olives, beer, grapes, raisins, peas, beans, barley, oats, rice, and wheat. It has been detected in processed food such as cheese, wine, grape juice, powdered milk, fruits, wine black pepper, and grape juice [8,23-25]. Ochratoxin $\mathrm{A}$ is isolated from meats of poultry and swine consuming contaminated feed [26], and has been detected in human blood and milk [27-29]. This indicates the widespread occurrence, and saprophytic and or parasitic nature of the black Aspergillus species.

Aspergillus niger var. niger and A. carbonarius are two major producers of ochratoxin A. For example, $25 \%$ to $100 \%$ of the isolates of A. carbonarius are ochratoxigenic, and 0.6 to $50 \%$ of the isolates of A. niger var. niger are ochratoxigenic [13]. Recent surveys indicate that these two black-spored aspergilli are the main source of ochratoxin A in major food products, including maize and wheat, in both tropical and subtropical zones of the world [30,31]. Curiously, the $A$. niger strains that do produce ochratoxin have been placed in the type N RFLP pattern, while ochratoxin production is not associated with strains from the type T RFLP stains [32]. However, this difference might reflect nutritional requirement in culture as to those required on natural substrates [33]. Both A. niger, var. niger and A. carbonarius are common in the United States [9,15], along with other ochratoxigenic species, A. foetidus, and A. tubingensis, but their ability to produce the ochratoxins is unknown. However, the species as currently defined that occur on maize and peanuts or grapes have not been identified, nor has ochratoxin production been established on maize or peanuts by these species.

In the past, the occurrence of ochratoxin $\mathrm{A}$ in maize has always indicated that the maize was contaminated during storage and that the maize was grown in a temperate climate because the fungi that produce it, mainly A. ochraceus, Penicillium verrucosum, and P. nordicum, [34,35], grow well under cool to cold conditions. Currently, additional temperate species are indicated as being able to produce ochratoxin A and B. These include A. alliaceus, a. sclerotiorum, A. sulphureus, a. albertensis, A. auricomus, A. melleus, A. glaucus, A. wentii, Neopetromyces muricatus, and A. westerdijkiae [34-36] Members of a different Aspergillus section, the Aspergillus section Nigri (formerly known as A. niger aggregate) have now been isolated from maize and peanuts (Table 2). The Aspergillus section Nigri group occurs in the warmer temperate and tropical zones [9]. The highest percentages of ochratoxigenic strains were found within the A. section Nigri [37], the taxa responsible for the main source of ochratoxin A in animal feeds, especially in locations with less than desirable storage and humidity-temperature conditions $[20,38]$. Surveys of poultry feed and the poultry environment indicated that the most frequently isolated fungus, second to $F$. verticillioides, was a black-spored species of the A. niger aggregate $[39,40]$. Maize and mixed diets prepared with maize, especially for poultry, contain a high number of $A$. niger CFU [39-41]. In Georgia, a black spored species, e.g., A. niger var. niger, is a major pathogen of peanuts, causing seedling blight of all the major cultivars. However, there are additional species that are found in lesser frequencies (Table 3) [15]. The problem is compounded because maize is a rotational crop for peanuts in several areas of the state, which results in infected maize. Neither the precise identify of the pathogen nor has the biological nature of this association been defined. Thus, ochratoxin A potentially can occur throughout the temperate, tropical, and subtropical climates of the world. 


\subsection{Fumonisins}

Additional toxic substances are presented in Table 1. It was recently discovered that four strains of A. niger were able to produce another type of mycotoxins, the fumonisins, which are commonly associated with strains of the maize pathogen Fusarium verticillioides (Gibberella moniliformis) and other Fusarium species [42]. Fusarium verticillioides-contaminated maize is correlated with human esophageal cancer, and the fumonisins are highly toxic to horses, pigs, and poultry [43]. The fumonisin mycotoxins are carcinogenic, although $B_{2}$ is more cytotoxic than $B_{1}$. The most commonly isolated fumonisin is the $B_{1}$ homologue, while $\mathrm{B}_{2}$ is isolated less frequently. Only strains of $A$. niger var. niger have currently been shown to produce the fumonisins including $\mathrm{B}_{4}$ and the new $\mathrm{B}_{6}$ homologue $[34,37,44]$. So far only the strains of $A$. niger var. niger from grapes have been reported as producers of the fumonisins. A survey of black aspergilli isolated from raisins indicated that $77 \%$ of $A$. niger from grapes produced fumonisin $\mathrm{B}_{2}$ and $\mathrm{B}_{4}$, and interestingly none of these strains produced the ochratoxins $[34,44]$, suggesting that the ability to produce each mycotoxin is entirely separate of conditions and depends on the genetics of a strain. Recently, another fumonisin homologue, fumonisin $\mathrm{B}_{6}$, was isolated from A. niger, with in general the frequencies of production of fumonisins in this species so far are $100 \% \mathrm{FB}_{2}, 10-25 \% \mathrm{FB}_{4}$, and 5-10\% $\mathrm{FB}_{6}$ [37]. The black aspergilli are co-isolated with $F$. verticillioides from maize and peanuts suggesting that the source of fumonisin accumulation on these substrates might be derived from either fungus. However, the production of strains of $A$. niger var. niger from maize has not been demonstrated. Since the black aspergilli, especially A. niger var. niger, are used in so many biotechnological processes for food use, the production of the fumonisins by the commonly occurrence of this species increases the concern for food safety.

Table 3. Species of black spored aspergilli isolated from surface sterilized maize kernels and peanuts samples obtained from the Midwest, and South Georgia, USA.

\begin{tabular}{lcc}
\hline \multirow{2}{*}{ Aspergillus Species } & \multicolumn{2}{c}{ \% Isolation Frequency } \\
\cline { 2 - 3 } & Maize & Peanuts \\
\hline A. niger & 95 & 67 \\
A. foetidus & - & 20 \\
A. japonicus & 5 & 13 \\
\hline \multicolumn{2}{c}{${ }^{\mathrm{a}}$ Data modified from Palencia et al. $[15]}$.
\end{tabular}

\subsection{Other mycotoxins}

The black aspergilli have produced a variety of biologically active compounds [36], some of which are phytotoxic. One not indicated as being produced by the black aspergilli in the extensive review is penicillic acid, which we consider important not only for it biological activity as a mycotoxin but also due to its numerous other properties. These properties are reviewed with the hope that attention is drawn to it as a metabolite of the black aspergilli. Penicillic acid $\left(\gamma\right.$-keto- $\beta$-methoxy- $\delta$-methylene- $A^{\alpha}$-henenoic acid) is particularly produced by most of the golden colored species of section Circumdati $(=A$. ochraceus group), and is oftentimes co-produced with ochratoxin A by strains of $A$. ochraceus [40,45]. Besides the A. ochraceus group, penicillic acid is also produced by numerous other species of Aspergillus and 
Penicillium [45-47], which suggest that penicillic acid is ubiquitous in strains and species of other subsections of these two genera. Penicillic acid is mycotoxic and synergistic with ochratoxin A in several animal studies [48-50], and phytotoxic to seedlings [51,52]. While the production of penicillic acid has not been reported in the most recent review of secondary metabolites reported in the black aspergilli [36], its production might explain a role for this species in this subsection as pathogens in several seedling diseases.

Penicillic acid is also inhibitory with microorganisms, particularly Gram-negative bacteria [53], and may be intricately involved with competition and ecological success of producing species. Recently, penicillic acid was established as an effective quorum sensing inhibitor [54,55], therefore interfering with cellular communication, and producing disruptive effects on virulence expression by pathogenic species, especially Gram-negative species. Its mode of action with bacteria might reflect it activity as an inhibitor of quorum sensing. Quorum sensing affects cellular activities of bacteria by interfering with several aspects of bacterial metabolism ranging from those necessary for growth to those responsible for cellular motility [54,56] to biofilm formation [57]. However, it is argued that quorum sensing is highly specific and it probably cannot be broadly applied to control all bacteria where quorum sensing is expressed [58]. This range of biological activity for penicillic acid indicates several desirable pharmacological benefits such as quorum sensing to undesirable one such as an inhibitor to bacteria used as biocontrol agents against penicillic acid positive pathogenic fungi. Penicillic acid therefore should be viewed also as an antibiotic where it mode of microbial antagonism is one of interfering with important signaling mechanisms used by colonizing bacteria, conceivably reducing their competition with the producing Aspergillus species. Since the biological activities described for penicillic acid above are important from several control measures, its production by the black aspergilli should be investigated.

\section{Host Associations and Plant Pathology}

Black aspergilli are reported as pre- and post-harvest pathogens in maize, other cereal grain, bunch grapes, onions, garlic, soya beans, apples, mangoes, and peanuts [16,41,59-61], although the extent of damage on each host depends on unknown predisposing environmental factors. The inoculum source of most species is the soil and litter, particular the vineyards soils [9,62-64]. Other sources include the seed of most crops [15,62] or fruit [63]. Most black aspergilli are indicated as opportunistic pathogens of fruits such as grapes and some spices [62,63]. In a small survey [15], several species of black aspergilli were isolated from surface disinfected maize and peanuts, which indicated that these species were endophytes. Endophytic associations have also been reported in onions and garlic [62], although these were characterized as latent infections. The better term for these infections is symptomless, as endophytic infections have proved in all instances as not latent or dormant as implied, but metabolically active, colonizing the host producing several classes of secondary metabolites, some of which are toxic. The major difference is the absence of disease symptoms produced during these infections. These endophytic infections can become, however, pathogenic under some biotic and abiotic conditions either pre- or post-harvest. Symptomless infections pose grave problems from a food safety concern, as commodities contaminated by such infections are not obvious, appear normal, but can contain toxic metabolites. 
An investigation of the endophytic nature of maize seedling was investigated. Aspergillus carbonarius SRRC 2131 and A. niger var. niger SRRC 13 were transformed with a yellow fluorescent protein vector that was used to measure colonization of maize seedlings $[15,65]$. The transformed black aspergilli did not affect the ability of these strains to colonize maize seedling (Figure 2). These transformed species were isolated from surface disinfected seedling roots and leaves of plants grown under ideal growth room conditions, and there were no significant differences in seedling height and stem thickness [15]. The infection remained symptomless and attempts at inducing seedling blight by inducing drought did not produce the disease. The endophytic nature of the black aspergilli was indicated from the recovery of A. niger from surface disinfected plant materials of onions by Hayden and Maude [62]. The infection in onion was also symptomless and infection was proved to develop from contaminated onion seed. Seedling onions were, as in the maize seedlings, similar to non-infected except in shoot length [62].

Figure 2. Aspergillus carbonarius SRRC2131 transformed with yellow fluorescent protein growing on potato dextrose agar medium (A) and in the roots of maize seedlings, illustrating the symptomless endophytic colonization of maize following the soil inoculation with the fungus (B), which persists even under drought conditions [65].

(A)

(B)

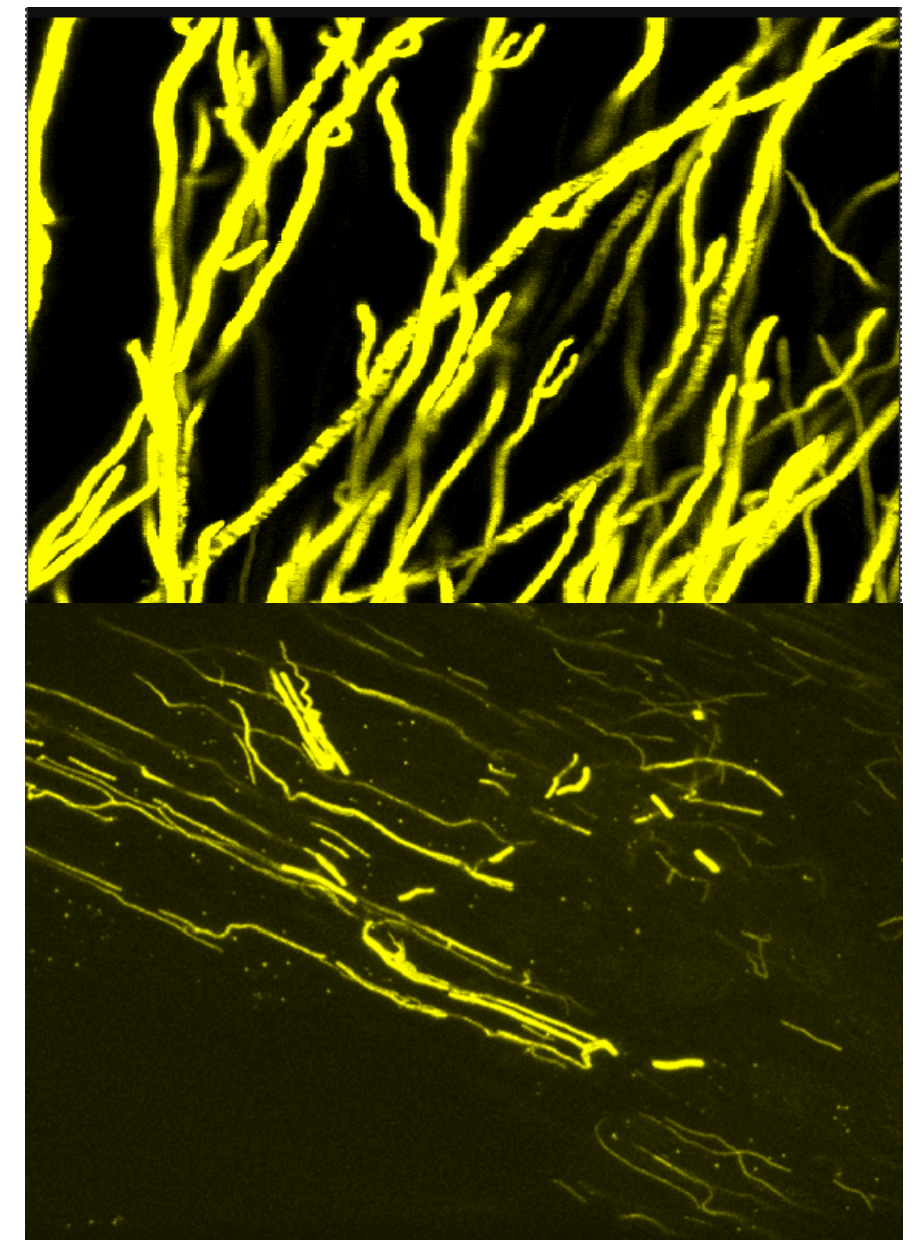


In grapes, another situation is described. Aspergillus rot in grapes is caused by the black species, A. niger, var. niger, A. carbonarius and A. aculeatus [63]. These black aspergilli are reported as opportunistic pathogens of damaged berries of grapes, since in the absence of damaged spores remain over the surface of grapes without causing visible pathology. Further, A. niger is known to cause kernel rot of maize (Figure 3), which is similar to ear/kernel rot produced by Fusarium verticillioides, and F. graminearum. However, black aspergilli are isolated from surface disinfected kernels of maize (Figure 4). Symptomless infections in onion by A. niger var. niger can develop into a postharvest disease, but perhaps due to injury to the bulbs or unsuited storage conditions $[62,66]$. In the case of maize, infection and the resulting kernel rot may occur from wounds produced by earworms and other damaging insects, similar to that which occurs from infections by A. flavus. Nevertheless, endophytic infections do occur as demonstrated from isolations from surface disinfected kernels, and these endophytic infections can colonize plant tissue. Therefore, some black aspergilli are capable of a biotrophic endophytic existence with maize and onion. Since these two plants are widely separated taxonomically, it is possible that endophytic infection by the black aspergilli exist in numerous plant taxa.

Figure 3. Maize kernel rot produced by Aspergillus niger.

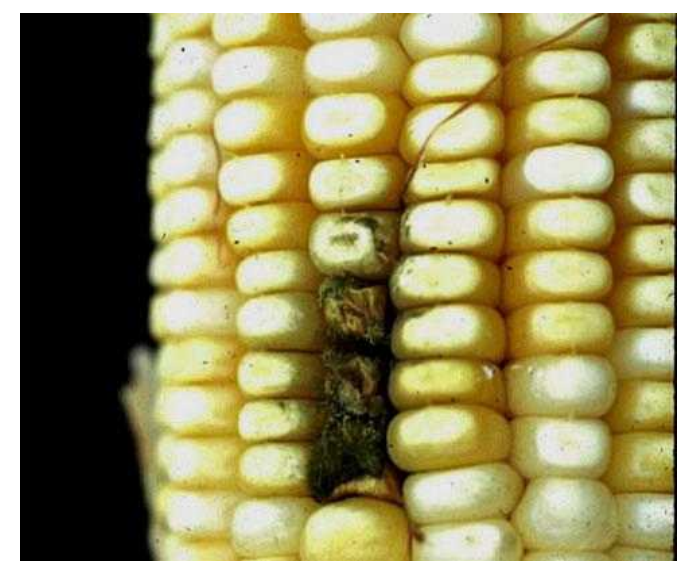

Figure 4. Isolation of black Aspergillus sp from surface disinfected field maize kernels, showing a black Aspergillus species (arrows) along with A. ochraceus growing from maize kernels on an isolation medium.

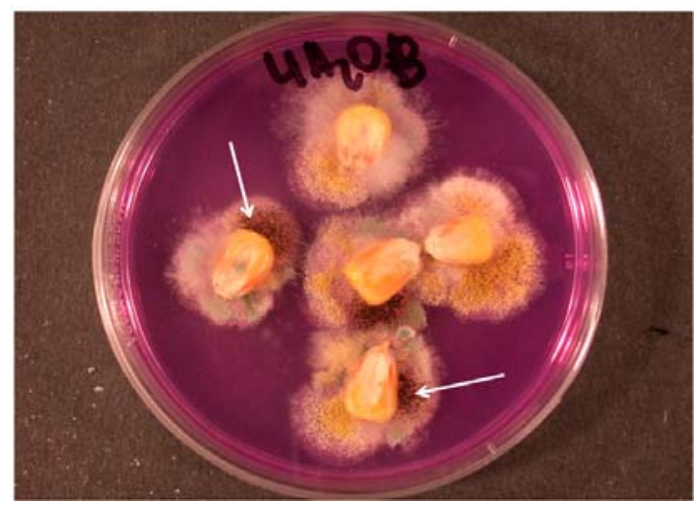


Since ochratoxin A is present in maize, and other cereal grain under field conditions [16], there is a suggestion that the black aspergilli species may form some relationship with maize during its growth under field conditions or that it is interactive with other field fungi. In a laboratory study, it was demonstrated that the fumonisin-producing fungi, F. verticillioides, can exclude the Aspergillus species such as $A$. niger var. niger, from colonizing maize, but this depended on optimum temperature and specific water activity levels $[67,68]$. The interaction of antagonistic substances was not examined in that study, but conceivable competition may also relate to inhibitory substances as well as the abiotic factors measured.

\section{Conclusions}

In the past most descriptions and concerns relative to the black aspergilli have been referred to as A. niger, resulting in a great deal of confusions concerning the actual species observed. Recent molecular analysis of the black aspergilli indicated several cryptic species, which now should be aligned with recent phytopathological and toxicological concerns. To prevent this confusion, the older A. niger has been replaced by A. niger, var. niger in order to exclude the prior confusion in discussions of both the earlier and recent discriptions. The subgenus Circumdati section Nigri consists of at least 19 species of black spore species of which A. niger var. niger is probably the most dominant species in the US where it is found in most soil types and on dozens of fruits and cereal grains. Of major concern is the relationship of the black aspergilli with maize and peanuts, two plants of major economic concern in the US Strains of A. niger var. niger, along with others, can produce the ochratoxins and the fumonisin $\mathrm{B}_{1}$ mycotoxins. In addition to the effect of the mycotoxins on animals and humans, these toxins are interactive with other secondary metabolites to produce synergistic effects. Others are also phytotoxic [69], suggesting role for this mycotoxin in the pathology of seedling blight of peanuts and maize. The production of both the ochratoxins and the fumonisins by the black aspergilli extends the concern since food and feeds not inductive to one mycotoxin can be inductive to the other. Similarly, attempts at control of one might not control the other. Current disease descriptions are based on the casual identification of the black aspergilli as belonging to the older descriptions of $A$. niger. Certain species have been characterized as producing specific toxins and associated pathology. This indicates the need for reexamination of taxa associated with specific food crops. Additionally, detailed studies of their host relationship are also indicated, as some species are associated with crops as symptomless endophytes. There are also reports on the co-occurrence of both ochratoxin A with the fumonisins in maize [70,71], which suggests interactions between producing endophytic fungi on maize, such as the maize endophyte F. verticillioides. Further, evidence of co-infection of $A$. niger with $A$. ochraceus in maize is observed also a concern as this presents difficulty in identifying the correct offending mycotoxic species. The black aspergilli are known pathogens in peanut culture where major problems are indicated from the seedling stage or during peanut set late in matured plants. The result is poor quality nuts that are rated too low for human consumption. Thus, pathogenic expressions in maize, cotton, grapes, peanuts and other plants, the production of the ochratoxins and fumonisins on these products, and the unknown species associated with specific pathological expressions on these important crop plants underlines the need for further studies of the black aspergilli. Finally, the 
prediction of rising global temperatures should influence the population patterns and shifts of species within the A. niger group to more northern latitudes that should increase the number of additional crops, adding to the mycotoxigenic potential globally for all species of the subgenera Circumdata.

\section{References}

1 Micheli, P.A. Nova Plantarum General Juxta Tournefortii Methodum Disposita; Typis Bernardi Paperinii: Florence, Italy, 1729.

2 Link, H F. Observationes in Ordines Plantarum Naturales; Gesellschaft Naturforschender Freunde zu: Berlin, Germany, 1809; 3, 1-42.

3 Forgacs, J.; Carll, W.T. Mycotoxicoses. Adv. Vet. Sci. 1962, 7, 273-382.

4 Allcroft, R.C.R.B.; Sargent, K.; O'Kelly, J. A toxic factor in Brazilian groundnut meal. Vet. Rec. 1961, 73, 428.

5 Sargeant, K.; Sheridan, A.; O'Kelly, J.; Carnaghan, R.B.A. Toxicity assocaited with certain samples of groundnuts. Nature 1961, 192, 1096.

6 van der Merve, K.J.; Steyn, P.S.; Fourie, L. The constitution of ochratoxin A, B, and C, metabolites of Aspergillus ochraceus Wilh. J. Chem. Soc. 1965, 7083-7088.

7 Hamilton, P.B.; Huff, W.E.; Harris, J.R.; Wyatt, R.D. Natural occurrences of ochratoxicoses in poultry. Poult. Sci. 1982, 61, 1832-1841.

8 Abarca, M.L.; Bragulat, M.R.; Castella, G.; Cabanes, F.J. Ochratoxin A production by strains of Aspergillus niger var. niger. Appl. Environ. Microbiol. 1994, 60, 2650-2652.

9 Klich, M.A. Biogeography of Aspergillus species in soil and litter. Mycologia 2002, 94, 21-27.

10 Raper, K.B.; Fennell, D.I. Aspregillus niger Group. In The Genus Aspergillus; Raper, K.B., Fennell, D.I., Eds.; The Williams \& Wilkins Co.: Baltimore, USA, 1965; Chapter 16, pp. 293-344.

11. Samson, R.A.; Varga, J. Molecular systematics of Aspergillus and its teleomophs. In Aspergillus: Molecular Biology and Genomics; Machida, M.; Gomi, K., Eds.; Caister Academic Press: Tsukuba, Ibaraki, Japan, 2010; pp. 20-25.

12. Abarca, M.L.F.; Accensi, F.; Cano, J.; Cabanes, F.J. Taxonomy and significance of black aspergilli. Anton. Van Leeuwen. 2004, 86, 33-49.

13. Accensi, F.; Abarca, M.L.; Cano, J.; Figuera, L.; Cabanes, F.J. Distribution of ochratoxin A producing strains in the A. niver aggregate. Antonie Van Leeuwenhoek 2001, 79, 365-370.

14. Samson, R.A.; Houbraken, J.; kuijpers, A.; Frank, J.M.; Frisvad, J.C. New ochratoxin or sclerotium producing species in Aspergillus section Nigra. Stud. Mycol. 2004, 50, 45-61.

15. Palencia, E.R.; Klich, M.A.; Glenn, A.E.; Bacon, C.W. Use of a rep PCR system to predict species in the Aspergillus section Nigri. J. Microbiol. Methods 2009, 79, 1-7.

16. Magnoli, C.; Hallak, C.; Astoreca, A.; Ponsone, L.; Chiacchiera, S.; Dalcero, A.M. Occurrence of ochratoxin A-producing fungi in commercial corn kernels in Argentina. Mycopathologia 2006, 161, $53-58$.

17. Frischbier, C.T.; Richtesteiger, R. Bildung von oxalsaure durch Aspergillus niger in Brot and in der streu. S. Veterinark. 1941, 53, 391. 
18. Wilson, B.J.; Wilson, C.H. Oxalate formation in moldy feedstuffs as a possible factor in livestock toxic disease. Am. J. Vet. Res. 1961, 21, 261-269.

19. International Agency on Research on Cancer Some naturally occurring substances: Food items and constitutents, heterocyclic aromatic amines and mycotoxins. IRRC 1993.

20. Castegnaro, M.; Canadas, T.; Vrabcheva, T.; Petkova-Bocharova, T.; Chernozemsky, I.N.; PfohlLeszkowicz, P. Balkan endemic nephropathy: Role of ochratoxin A through biomarkers. Mol. Nutri. Food Res. 2005, 50, 519-529.

21. Lambert, D.; Padfield, P.J.; McLaughlin, S.; Cannell, S.; O'Neill, C.A. Ochratoxin A displaces claudins from detergent resistant membrane microdomains. Biochem. Biophys. Res. Commun. 2007, 358, 632-636.

22. Shotwell, O.L.; Hesseltine, C.W.; Goulden, M.L. Ochratoxin A: Occurrence as natural contaminant of a corn sample. Appl. Microbiol. 1981, 17, 765-766.

23. Accensi, F.; Abarca, M.L.; Cano, J.; Figuera, L.; Cabanes, F.J. Ochratoxin A producing strains in the Aspergillus niger aggregate. Antonie Van Leeuwenhoek 2001, 79, 365-370.

24. Bennett, J.W.; Klich, M.A. Mycotoxins. Clin. Microbiol. Rev. 2003, 16, 497-516.

25. Rosa, C.A.R.; Ribeiro, J.M.M.; Fraga, M.J.; Gattuso, M.A.; Cavaglieri, L.R.; Magnoli, C.E.; Dalcero, A.M.; Lopes, C.W.G. Mycoflora of poultry feeds and ochratoxin-producing ability of isolated Aspergillus and Penicillium species. Vet. Microbiol. 2006, 113, 89-96.

26. Dalcero, A.; Magnoli, C.; Hallak, C.; Chiacchiera, S.M.; Palacio, G.; Rosa, C.A.R. Detection of ochratoxin A in animal feeds and capacity to produce this mycotoxin by Aspergillus section Nigri in Argentina. Food Addit. Contam. 2002, 19, 1065-1072.

27. Puntaric, D.; Bosnir, J.; Smit, Z.; Skes, I.; Baklaic, Z. Ochratoxin A in corn and wheat: Georgraphical association with endemic nephropathy. Croatian Med. J. 2001, 42, 175-180.

28. Kuiper-Goodman, T. Risk assessment of ochratoxin A residues in food. IARC Sci. Publ. 1991, 115, 307-320.

29. Domijan, A.M.; Peraica, M.; Fuchs, R.; Lucic, A.; Radic, B.; Balija, M. Ochratoxin A in blood of healthy population in Zagrab. Arh. Hig. Rada. Tokskol. 1999, 50, 263-271.

30. Rosa, C.A.R.; Ribeiro, J.M.M.; Fraga, M.J.; Gatti, M.; Cavaglieri, L.R.; Magnoli, C.E.; Dalcero, A.M.; Lopes, C.W.G. Mycoflora of poultry feeds and ochratoxin-producing ability of isolated Aspergillus and Penicillium species. Vet. Microbiol. 2006, 113, 89-96.

31. Hajjaji, A.; El Otmani, M.; Bouya, D.; Bouseta, A.; Mathieu, F.; Collin, S.; Lebrihi, A. Occurrence of mycotoxins (Ochratoxin A, deoxynivalenol) and toxigenic fungi in Moroccan wheat grains: Impact of ecological factors on the growth and ochratoxin A production. Mol. Nutri. Food Res. 2006, 50, 494-499.

32. Accensi, F.; Cano, J.; Figuera, L.; Abaca, M.L.; Cabanes, F.J. New PCR method to differentiate species in the Aspergillus niger aggregate. FEMS Microbiol. Lett. 1999, 180, 191-196.

33. Medina, A.; Mateo, R.; Lopez-Ocana, L.; Valle-Algarra, F.M. Study of Spanish grape microbiota and ochratoxin A production by isolates of Aspergillus tubingensis and other members of Aspergillus section nigri. Appl. Environ. Microbiol. 2005, 71, 4696-4702. 
34. Frisvad, J.C.; Smedsgaard, J.; Samson, R.A.; Larsen, T.O.; Trane, U. Fumonisin B2 Production by Aspergillus niger. J. Agric. Food Chem. 2007, 55, 9727-9732.

35. Frisvad, J.C.; Frank, J.M.; Houbraken, J.A.M.P.; Kuijpers, A.F.A.; Samson, R.A. New ochratoxin A producing species of Aspergillus section circumdati. Stud. Mycol. 2004, 50, $23-24$.

36. Nielsen, K.F.; Mogensen, J.M.; Larsen, T.O.; Frisvad, J.C. Review of secondary metabolites and mycotoxins from the Aspergillus group. Anal. Bioanal. Chem. 2009, 395, 1225-1242.

37. Mansson, M.; Klejnstrup, M.L.; Phipps, R.K.; Nielsen, K.F.; Frisvad, J.C.; Gotfredsen, C.H.; Larsen, T.O. Isolation and NMR chracterization of fumonisin $\mathrm{B}_{2}$ and a new fumonisin $\mathrm{B}_{6}$ from Aspergillus niger. J. Agric. Food Chem. 2010, 58, 949-953.

38. Magan, N.; Aldrich, C.G. Conditions of formation of ochratoxin A in drying, transport and in different commodities. Food Addit. Contam. 2005, 1, 10-16.

39. Bacon, C.W.; Burdick, D. The growth of fungi in broiler houses. Poult. Sci. 1977, 56, 653-661.

40. Bacon, C.W.; Sweeny, J.G.; Robbins, J.D.; Burdick, D. Production of penicillic acid and ochratoxin A on poultry feed and capacity to produce this mycotoxin in Aspergillus section Nigri in Argentina. Appl. Microbiol. 1973, 26, 155-160.

41. Balcero, A.; Magnoli, C.; Hallak, C.; Ciacchiera, G.; Palacio, G.; Rosa, C.A.R. Detection of ochratoxin A in animal feed and capacity to produce this mycotoxin in Aspergillus section nigri in Argentina. Food Addit.Contam. 2002, 19, 1065-1072.

42. Gelderblom, W.C.A.; Jaskiewicz, K.; Marasas, W.F.O.; Thiel, P.G.; Horak, R.M.; Vleggar, R.; Kriek, N.P.J. Fumonisins--novel mycotoxins with cancer-promoting activity produced by Fusarium moniliforme. Appl. Environ. Microbiol. 1988, 54, 1806-1811.

43. Riley, R.T.; Norred, W.P.; Bacon, C.W. Fungal toxins in foods: Recent concerns. Annu. Rev. Nutr. 1993, 13, 167-189.

44. Noonim, P.; Wahakarnchanakul, W.; Nielsen, K.F; Frisvad, K.F.; Samson, R.A. Fumonisin B2 production by Aspergillus niger in Thai coffee beans. Food Addit. Contam. Part A 2009, 26, 94-100.

45. Lindenfelser, L.A.; Ciegler, A. Penicillic acid production in submerged culture. Appl. Environ. Microbiol. 1977, 34, 553-556.

46. Ciegler, A. Bioproduction of ochratoxin and penicillic acid by members of the Aspergillus ochraceus group. Can. J. Microbiol. 1972, 18, 631-636.

47. Birkinshaw, J.H.; Oxforn, A.E.; Raistrick, H. Studies in the biochemistry of microorganisms. XLVIII. Penicillic acid, a metabolic products of Penicillium puberculum Banier and P. cyclopium Westling. Biochem. J. 1936, 30, 394-411.

48. Kubena, L.F.; Phillips, T.D.; Witzel, D.A.; Heidelbaugh, N.D. Toxicity of ochratoxin A and penicillic acid to chicks. Bull. Environ. Contam. Toxicol. 1984, 32, 711-716.

49. Sansing, G.; Lillehoe, E.; Detroy, R.; Muller, M. Synergistic toxic effects of citrinum, ochratoxin A, and penicillic acid in mice. Toxicon 1976, 14, 213-220.

50. Shepherd, E.; Philips, T.; Joiner, G.; Kubena, L.; Heidelbaugh, N. Ochratoxin A and Penicillic acid interaction in mice. J. Environ. Sci. Health 1981, B16, 557-573. 
51. Jamaji, K.; Fukushi, Y.; Hashidoko, Y.; Tahara, S. Penicillium frequentans isolated from Picea glehnii seedling roots as a possible biological control agent against damping-off. Ecol. Res. 2005, 20, 103-107.

52. Cole, R.J.; Cox, R.H. Handbook of toxic fungal metabolites; Academic Press: New York, NY, USA, 1981.

53. Heatley, N.G.; Philpot, F.J. The routine examination for antibiotics produced by moulds. J. Gen. Microbiol. 1947, 1, 232-237.

54. Rasmussen, T.B.; Givskov, M. Quorum sensing inhibitors: A bargan of effects. Microbiology 2006, 152, 1325-1340.

55. Rasmussen, T.B.; Skindersoe, M.E.; Bjarnsholt, T.; Phipps, R.K.; Christensen, K.B.; Jensen, P.O.; Andersen, J.B.; Larsen, T.O.; Hentzer, M.; Hoiby, N.; Givskov, M. Identity and effects of quorumsensing inhibitors produced by Penicillium species. Microbiology 2005, 151, 1325-1340.

56. Uroz, S.; Dessaux, Y.; Oger, P. Quorum sensing and quorum quenching: The yin and yang of bacterial communication. Chembiochem 2009, 10, 205-216.

57. Liaqat, I.; Bachmann, T.R.; Sabri, A.N.; Edyvean, G.J.; Biggs, C.A. Investigating the effect of patulin, penicillic acid and EDTA on biofilm formation of isolates from dental unit water lines. Appl. Microbiol. Biotechnol. 2008, 81, 349-358.

58. Rasch, M.; Rasmussen, T.B.; Andersen, J.B.; Persson, T.; Givskov, J.; Givskov, M.; Gram, L. Wellknown quorum sensing inhibitors do not affect bacterial quorum sensing-regulated bean sprout spoilage. J. Appl. Microbiol. 2007, 102, 826-837.

59. Pitt, J.I. Xerophilic Fungi and the Spoilage of Foods of Plant Origin; Duckworth, R.B., Ed.; Academic press: New York, NY, USA, 1975; pp. 273-307.

60. Pozzi, C.R.; Correa, B.; Gambale, W.; Paula, C.A.; Chancon-Reche, N.O.; Carlos, M.; Meirelles, C.A. Postharvest and stored corn in Brazil: Mycoflora interactions, abiotic factors and mycotoxin occurrence. Food Addit. Contam. 1995, 12, 313-319.

61. Magnoli, C.E.; Saenz, M.A.; Chiacchiera, S.M.; Dalcero, A.M. Natural occurrence of Fusarium species and fumonisin-production by toxigenic strains isolated from poultry feeds in Argentina. Mycopathologia 1999, 145, 35-41.

62. Hayden, N.J.; Maude, R.B. The role of seed-borne Aspergillus niger in transmission of black mould of onion. Plant Pathol. 1992, 41, 573-581.

63. Leong, S.L.; Hocking, A.D.; Scott, E.S. Aspergillus species producing ochratoxin A: Isolation from vineyard soils and infection of Semillo bunches in Australia. J. Appl. Microbiol. 2007, 102, 124-133.

64. Griffin, C.J.; Smith, E.P.; Robinson, T.J. Population patterns of Aspergillus flavus group and A. niger group in field soils. Soil Biol. Biochem. 2001, 33, 253-257.

65. Palencia, E.R.; Glenn, A.E.; Bacon, C.W. Colonization of maize seedlings under drought conditions by two ochratoxin A producer species within the section A. section Nigri. Phytopathology 2009, 99, S99. 
66. Burgess, L.M.; Knight, T.E.; Tesoriero, L.; VaPhan, H.T. Common Diseases of Some Economically Important Crops; Australian Centre for International Agricultural Research: Canberra, Australia, 2009; Vol. 11, pp. 166-167.

67. Marin, S.; Sanchis, V.; Rull, F.; Ramos, A.J.; Magan, N. Collinization of maize grain by Fusarium moniliforme and Fusarium proliferatum in the presence of competing fungi and their impact on fumonisin production. J. Food Prot. 1998, 61, 1489-1496.

68. Palacios-Cabrera, H.; Tanikawi, M.H.; Hashimoto, J.M.; de Menezes, H.C. Growth of Aspergillus ochraceus, A. carbonarium and A. niger on culture media at different water activites and temperatures. Brazilian J. Microbiol. 2005, 36, 24-28.

69. Glenn, A.E.; Zitomer, N.C.; Zimeri, A.M.; Williams, L.D.; Riley, R.T. Transformation-mediated complementation of a FUM gene cluster deletion in Fusarium verticilioides restores both fumonisin production and pathogenicity on maize seedlings. Mol. Plant Microbe Interact. 2008, 21, 87-97.

70. Scudamore, K.A.; Livesey, C.T. Occurrence and significance of mycotoxins in forage crops and silage: A review. J. Sci. Food Agric. 1998, 77, 1-17.

71. Park, J.W.; Kim, M.A.; Shon, D.H.; Kim, Y.B. Natural co-occurrence of aflatoxin B1, fumonisin B1 and ochratoxin A in barley and corn food from Korea. Food Addit. Contam. 2002, 19, 1073-1080.

72 Axxiz, N.H.; Youssef, A.Y.; El-Fouly, M.Z.; Moussa, L.A. Contamination of some common medicinal plant samples and spices by fungi and their mycotoxins. Bot. Bull. Acad. Sin. 1998, 39, 278-285.

(C) 2010 by the authors; licensee Molecular Diversity Preservation International, Basel, Switzerland. This article is an open-access article distributed under the terms and conditions of the Creative Commons Attribution license (http://creativecommons.org/licenses/by/3.0/). 